\title{
Removal of copper (II) by manganese-coated sand in a liquid fluidized-bed reactor
}

\author{
Chia-I Lee ${ }^{\mathrm{a}, *}$, Wan-Fa Yang ${ }^{\mathrm{a}}$, Cheng-I Hsieh $^{\mathrm{b}}$ \\ ${ }^{a}$ Graduate Institute of Environmental Engineering, National Taiwan University, Taipei 10673, Taiwan \\ ${ }^{\mathrm{b}}$ Department of Bioenvironmental Systems Engineering, National Taiwan University, Taipei 10673, Taiwan
}

Received 23 February 2004; received in revised form 5 May 2004; accepted 21 June 2004

Available online 27 September 2004

\begin{abstract}
This study was performed in a fluidized-bed reactor (FBR) filled with manganese-coated sand (MCS) to treat copper-contaminated wastewater. The adsorption characteristics of MCS, the adsorption equilibrium of MCS, and the copper removal capacity by MCS in FBR were investigated. In terms of the adsorption characteristics of MCS, the surface of MCS was evaluated using a scanning electron microscope (SEM). Energy dispersive analysis (EDS) of X-rays indicated the composition of MCS, and the quantity of manganese on MCS was determined by means of acid digestion analysis. The experimental results indicated that copper was removed by both sorption (ion exchange and adsorption) and coprecipitation on the surface of MCS in FBR. Copper removal efficiency was highly dependent on the pH and increased with increasing $\mathrm{pH}$ from $\mathrm{pH} 2$ to 8 . After the copper adsorption by MCS, the $\mathrm{pH}$ in solution was decreased. When the MCS concentration was greater than $10 \mathrm{~g} / \mathrm{l}$, the copper adsorptivities obtained by FBR were almost the same as that from the shaker and when the MCS concentration reached $40 \mathrm{~g} / \mathrm{l}$, the copper adsorptivity in FBR was greater than that from the shaker. The adsorption sites of MCS could be used efficiently by the FBR. A Langmuir adsorption isotherm equation fit the measured adsorption data from the batch equilibrium adsorption test better than the Freundlich adsorption isotherm equation did. In addition, the adsorption rate increased when the influent wastewater was aerated.
\end{abstract}

(C) 2004 Elsevier B.V. All rights reserved.

Keywords: Fluidized-bed reactor; Copper removal; Manganese-coated sand; Adsorption; Coprecipitation

\section{Introduction}

Heavy metal contamination exists in natural water, drinking water and waste streams of many industries. The primary sources of copper discharge from industries include printed circuit boards, metal surface treatments and mining operations. Heavy metals are not biodegradable and tend to accumulate in living organisms. Copper can cause stomach and intestinal distress, liver and kidney damage, and anemia [1]. Removing copper ions from water bodies is, then, an important process.

Conventional methods for treating metal-bearing water that contains copper ions employ the alkaline precipitation process. In this process, copper generally forms hydroxide

* Corresponding author. Tel.: +886 937162892; fax: +886 223626373 . E-mail address: d91541004@ntu.edu.tw (C.-I. Lee). precipitate, to which caustic is added to adjust the wastewater to an alkaline $\mathrm{pH}$, followed by precipitate forming and setting. This process usually generates huge amounts of waterrich sludge, which has to be disposed of continuously. In addition, the precipitation process can only reduce the dissolved metal concentration to the solubility product level, which often cannot meet the discharge permit standard, thus necessitating further polishing stages. Cost-effective alternative techniques or materials for the removal of copper ions from diluted solutions are, hence, needed [2].

Adsorption processes for the treatment of metal-bearing drinking water or wastewater are becoming attractive. The adsorption of heavy metal cations/anions onto synthetic oxides/oxyhydroxides of $\mathrm{Mn}, \mathrm{Fe}, \mathrm{Al}$, etc., has been studied extensively [3-8]. These multivalent hydrous oxides are amphoteric, and the charge of the hydrous oxide depends on the $\mathrm{pH}$ of the medium. $\mathrm{MnO}_{2}$ is one kind of surface acidic oxides, 
whose $\mathrm{pH}_{\mathrm{pzc}}$ (point of zero charge) value is about 2.0 [9]. Generally, manganese oxide's surface charge is negative, and it can be used as an adsorbent to remove heavy metals from tap water or wastewater. However, most metal oxides are available only as fine powders or are generated in aqueous suspension as hydroxide floc or gel. In such forms, these oxides retain adsorptive properties for heavy metals, but a sedimentation basin or filtration unit is needed for solid/liquid separation.

In recent years, the fluidized-bed reactor (FBR) technique process has been used as an alternative treatment method for heavy metal removal [10-15]. The process of crystallizing $\mathrm{CaCO}_{3}$ in an FBR was applied in the softening of drinking water [10]. Nielsen et al. [12] tested the fluidized-bed technique at a coal-fired power station with wastewater from a flue gas desulphurisation unit for the removal of heavy metals from wastewater. In this technique, manganese or ferrous ions and an oxidation agent (e.g., $\mathrm{O}_{2}, \mathrm{H}_{2} \mathrm{O}_{2}, \mathrm{KMnO}_{4}$ ) are continuously added to the wastewater. An adsorptive granule of either $\mathrm{FeOOH}$ (ferric oxyhydroxide) or manganese dioxide is generated as a coating on the surface of the carrier material. Furthermore, heavy metal removal [13-15] by means of the crystallization of carbonate in an FBR is employed to reduce the disposal of hydroxide sludge and reduce the cost of the metal involved.

In order to solve the solid/liquid separation problem and apply the above adsorption technology in practice, a cheap carrier material of manganese-coated sand (MCS) and an FBR are used. This study intended to remove copper ions from synthetic wastewater by using an FBR filled with MCS as a heavy metal stripper. During operation, the coppercontaminated wastewater was only subjected to $\mathrm{pH}$ value adjustment and was pumped vertically upward through the fluidized bed. The copper ions were removed by means of adsorption and coprecipitation on the surface of MCS in the
FBR. When the adsorptive capacity was saturated, the adsorbent could be withdrawn via a side-tube near the reactor bottom and replaced from the top of the reactor.

\section{Materials and methods}

\subsection{Material}

MCS (obtained from the Yow Shiuan Mining Co., Taiwan) was used as a carrier material (or absorbent), and the average diameter of the MCS was $1.0 \pm 0.1 \mathrm{~mm}$. The synthetic wastewater was prepared by dissolving $\mathrm{CuCl}_{2} \cdot \mathrm{H}_{2} \mathrm{O}$ (the Merck Co., Analytical Reagent Chemicals) in deionized water.

\subsection{Methods}

The experimental set-up is shown in Fig. 1. The FBR had an inner diameter of $0.03 \mathrm{~m}$ and a height of $1.5 \mathrm{~m}$ with a larger cross-sectional area of weir, and it was filled with a fixed amount of MCS. The experiment was begun with a 51 solution containing a fixed concentration of copper, and the solution $\mathrm{pH}$ was adjusted to a desired value using $0.1 \mathrm{~N} \mathrm{NaOH}$ or $0.1 \mathrm{~N} \mathrm{HNO}_{3}$.

The copper solution was pumped into the reactor vertically and fluidized the manganese sand bed at a flow rate of $10 \mathrm{~m} / \mathrm{h}$ with the temperature keep at room temperature, that is, about $25^{\circ} \mathrm{C}$. For measurement of the copper concentration, samples were taken from the influent and effluent of the FBR. After a specified period of time, the effluent solution was taken.

The adsorption isotherms of MCS for copper were carried out in $250 \mathrm{ml}$ high-density polyethylene (HDPE) bottle. A total amount of $100 \mathrm{ml}$ solution containing a fix concentration of copper was introduced into each bottle and a fixed amount

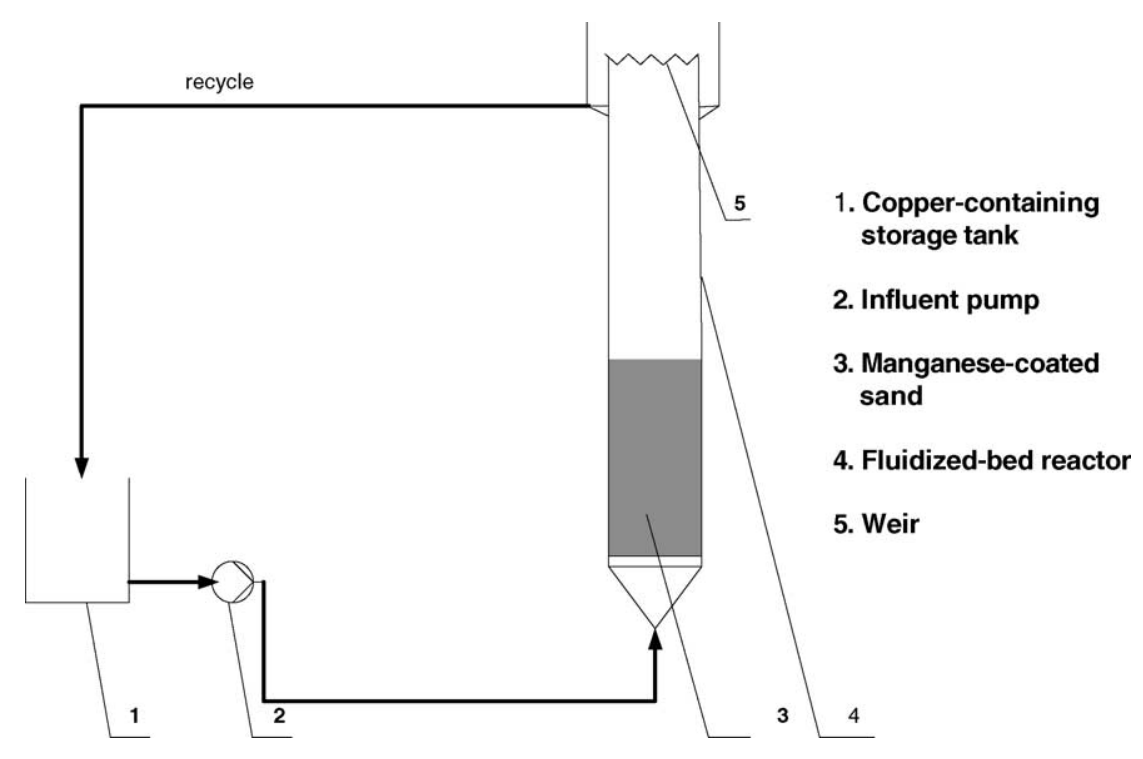

Fig. 1. Schematic drawing of the FBR. 


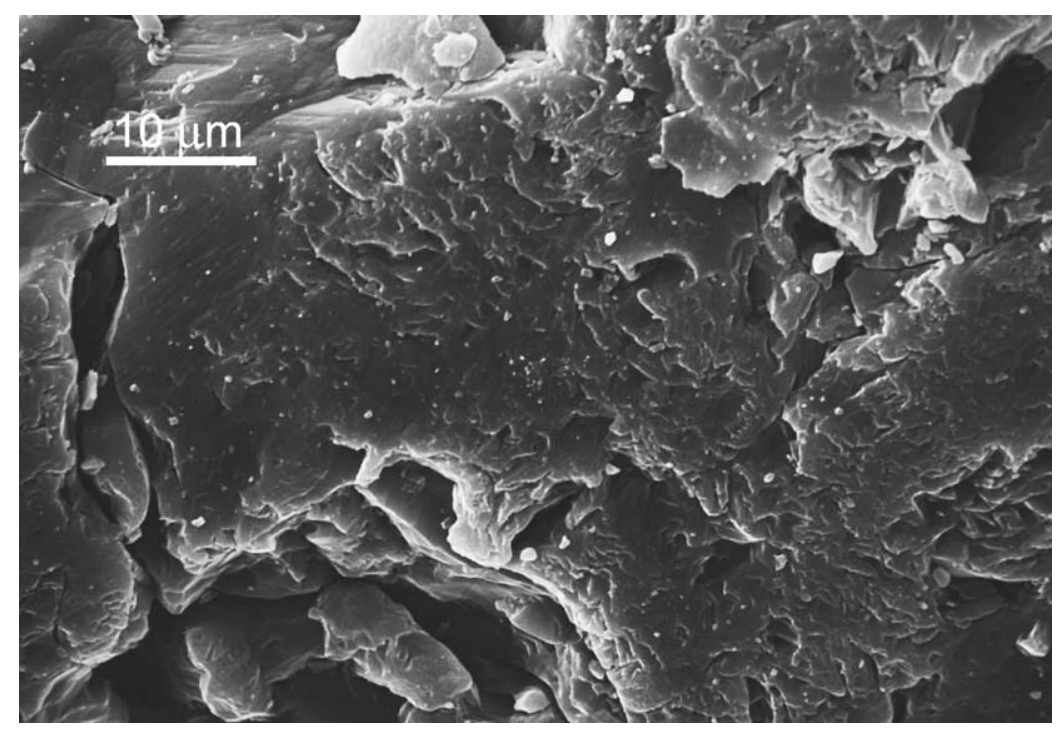

Fig. 2. SEM image of MCS.

of MCS was added. The solution $\mathrm{pH}$ was adjusted to 5.0 with $\mathrm{HNO}_{3}$ and $\mathrm{NaOH}$. The bottles were shaken (DENG YNG, Taiwan, ModelDKW-40L) at $25^{\circ} \mathrm{C}$, immersed in a water bath for $24 \mathrm{~h}$ to attain an equilibrium state, and the oscillatory velocity was $100 \mathrm{rpm}$.

The taken solution was filtered through Whatman 42 filter paper, filtrates were acidified using $\mathrm{HNO}_{3}$ and stored in a refrigerator at $4{ }^{\circ} \mathrm{C}$. The copper concentration in the filtrate was analysed using a flameless atomic absorption spectrometry spectrophotometer (Perkin-Elmer AAnalyst 800). The amount of copper removed was calculated indirectly based on the difference between the influent and effluent concentrations of the solutions. The $\mathrm{pH}$ of the solutions at the beginning and end of experiments was measured.

\subsection{Analysis of the surface characteristics of MCS}

The specific surface area of MCS was tested using the nitrogen adsorption method, and the BET adsorption model was used in the calculation. The surface shape and the composition of MCS were analysed using a scanning electron microscope with energy dispersive X-ray spectrum (SEM-EDS, PHILIPS). MCS samples for EDS analysis were coated with a thin carbon film to avoid the influence of any charge during the EDS operation.

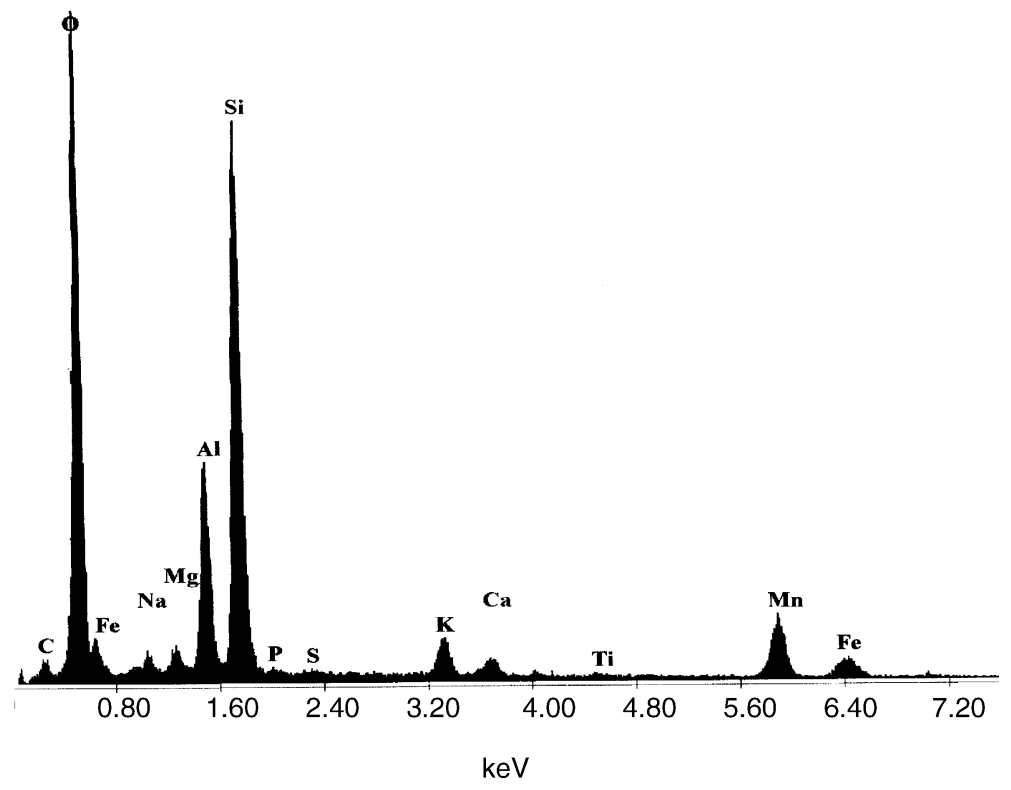

Fig. 3. EDS spectrum of MCS. 


\section{Results and discussion}

\subsection{Surface characteristics of MCS}

The MCS samples had common features, including silica sand and a brown color. The specific surface area was $9.03 \mathrm{~m}^{2} / \mathrm{g}$ obtained using the nitrogen adsorption method and the BET adsorption model. An SEM imagine of MCS is shown in Fig. 2. This figure reveals the common features of the MCS surface, which is a porous and irregular surface with aggregated particles.

The spectrum of MCS obtained through SEM-EDS elemental analysis is shown in Fig. 3, which indicates that besides manganese, the elements in MCS, including $\mathrm{Si}, \mathrm{Al}, \mathrm{Fe}$ and $\mathrm{Ti}$, have the potential for copper adsorption. The amount of manganese on the surface of the MCS, measured through acid digestion analysis, was approximately $8.03 \mathrm{mg} \mathrm{Mn} / \mathrm{g}$ MCS.

\subsection{Effect of the MCS concentration on copper removal}

The effects of the MCS concentration on the adsorption amount of $\mathrm{Cu}^{2+}$ adsorbed in the FBR and thermostated shaker are shown in Fig. 4. During each operation, the test was conducted for $24 \mathrm{~h}$.

In a shaker, the adsorption amount of copper, adsorbed decreased rapidly as the MCS concentration increased from 1 to $3 \mathrm{~g} / \mathrm{l}$ and remained constant above $15 \mathrm{~g} / \mathrm{l}$. In the FBR, the amount of copper adsorbed decreased slowly as the MCS concentration increased from 6 to $20 \mathrm{~g} / \mathrm{l}$. In this case, when the MCS concentration was larger than $10 \mathrm{~g} / \mathrm{l}$, the copper adsorptivity obtained in the FBR was almost the same as that from the shaker. However, when the MCS concentration was larger than $40 \mathrm{~g} / \mathrm{l}$, the FBR copper adsorptivity was greater than that from the shaker. When the MCS concentration was $40 \mathrm{~g} / \mathrm{l}$, the copper adsorptivity in the FBR and shaker were 0.816 and $0.773 \mathrm{mg} / \mathrm{g}$, respectively. These results demonstrate that

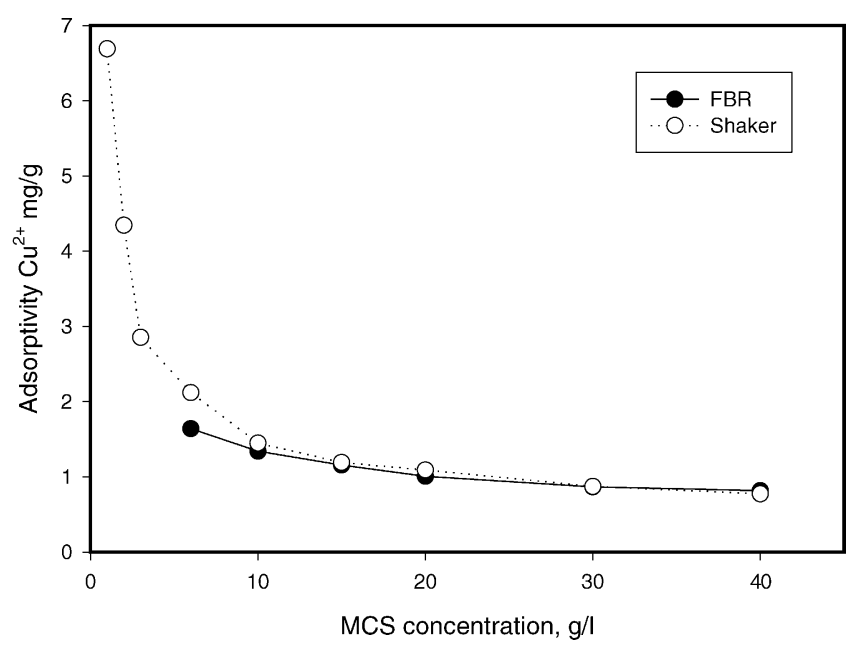

Fig. 4. Variation of the copper adsorption amount with the variation of the MCS concentration in the FBR and shaker $\left(\mathrm{pH}=6, C_{0}=30 \mathrm{Cu}^{2+} \mathrm{mg} / \mathrm{l}\right)$.

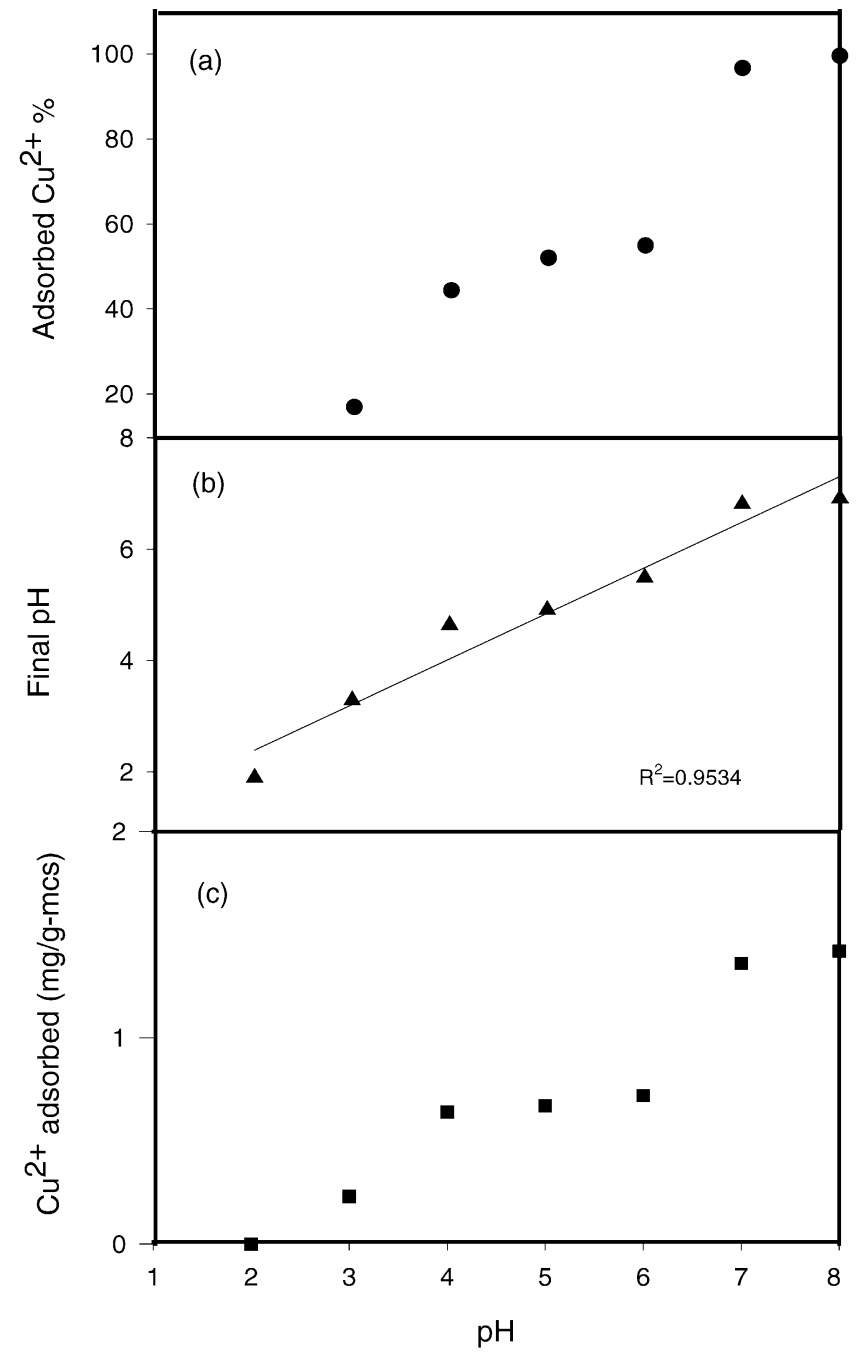

Fig. 5. Variation of $\mathrm{pH}$ and the adsorption of copper on MCS: (a) adsorbed $\mathrm{Cu}^{2+} \%$ at $\mathrm{pH}=2.0-8.0$ and $C_{0}=30 \mathrm{Cu}^{2+} \mathrm{mg} / \mathrm{l}$. (b) The relationship between initial and final $\mathrm{pHs}$, MCS concentration of $20 \mathrm{~g} / \mathrm{l}$; experiment duration of $1 \mathrm{~h}$ and $C_{0}=30 \mathrm{Cu}^{2+} \mathrm{mg} / \mathrm{l}$. (c) The adsorption of copper on MCS as a function of the $\mathrm{pH}$ value: $C_{0}=30 \mathrm{Cu}^{2+} \mathrm{mg} / \mathrm{l}$.

the adsorption sites of MCS could be used efficiently by the FBR.

\subsection{Effect of the $\mathrm{pH}$ and the change of $\mathrm{pH}$ value during $\mathrm{Cu}^{2+}$ adsorption on $\mathrm{MCS}$}

Fig. 5(a) shows the adsorption of copper onto MCS over a $\mathrm{pH}$ range of 2.0-8.0. The $\mathrm{pH}$ value was an important parameter controlling the adsorption of $\mathrm{Cu}^{2+}$ onto the surface of the MCS. The percentage of $\mathrm{Cu}^{2+}$ adsorbed increased as the $\mathrm{pH}$ value increased from $\mathrm{pH} 2$ to 6 , and at $\mathrm{pH} 6$, the percentage of adsorbed $\mathrm{Cu}^{2+}$ was $55 \%$.

The species distribution of copper in aqueous phase can be calculated using the formation constant $K_{i}$. Table 1 lists the related values of $\log K_{i}$ at $25^{\circ} \mathrm{C}$ and zero ionic strength [16].

Theoretical calculation shows that at an initial copper concentration of $30 \mathrm{mg} / \mathrm{l}$, free ions of $\mathrm{Cu}^{2+}$ are the dominant 
Table 1

The formation constants of copper and hydroxide $\left(\log K_{i}\right)$ in water at $25^{\circ} \mathrm{C}$ and zero ionic strength [16]

\begin{tabular}{lllll}
\hline $\mathrm{Cu}(\mathrm{OH})^{+}$ & $\mathrm{Cu}(\mathrm{OH})_{2}$ & $\mathrm{Cu}(\mathrm{OH})_{4}{ }^{2-}$ & $\mathrm{Cu}_{2}(\mathrm{OH})_{2}{ }^{2+}$ & $\mathrm{Cu}(\mathrm{OH})_{2(\mathrm{~s})}{ }^{\mathrm{a}}$ \\
\hline 6.3 & 11.8 & 16.4 & 17.7 & 19.3 \\
\hline${ }^{\text {a }}$ Solid or precipitate. & &
\end{tabular}

species when $\mathrm{pH}<6.01$. On the other hand, the precipitate $\mathrm{Cu}(\mathrm{OH})_{2(\mathrm{~s})}$ forms when $\mathrm{pH}>6.01$. In the result of copper removed, the initial $\mathrm{pH}$ was 7.0 and after a period of $1 \mathrm{~h}$ operation time, the residual copper concentration for total and soluble concentration was 9.25 and $0.95 \mathrm{mg} / \mathrm{l}$, respectively. The results indicated the greater part of copper were in the form of $\mathrm{Cu}(\mathrm{OH})_{2(\mathrm{~s})}$, and coated on the surface of MCS. In this situation, $\mathrm{Cu}^{2+}$ and $\mathrm{Cu}(\mathrm{OH})^{+}$are the major components in the solution when the $\mathrm{pH}$ value is less than 6.01. The $\mathrm{pH}_{\mathrm{zpc}}$ value of the MCS was found previously to be 2.0. This result indicates that when $2 \leq \mathrm{pH} \leq 6$, the MCS is negatively charged, and that the species of copper are $\mathrm{Cu}^{2+}$ and $\mathrm{Cu}(\mathrm{OH})^{+}$. Under such conditions, copper adsorption occurs by means of electrostatic attraction. At low $\mathrm{pH}$, the small amount copper adsorbed at low $\mathrm{pH}$ is probably due to competitive adsorption of $\mathrm{H}^{+}$with copper ions.

In addition, to understand the adsorption mechanism, the variation of $\mathrm{pH}$ in a solution and the copper adsorbed on MCS during adsorption were measured, and the results are shown in Fig. 5(b) and (c). The relationship between the initial $\mathrm{pH}$ range of 2.0-8.0 and the final $\mathrm{pH}$ values during $\mathrm{Cu}^{2+}$ adsorption on MCS was linear, and the $R^{2}$ value was 0.9534 . The $\mathrm{pH}$ of the solution was observed to be decreased after adsorption by MCS. During the adsorption experiment, the $\mathrm{pH}$ value of the solution changed from 2 to 1.9, from 6 to 5.5, and from 8 to 6.9. These results indicated that the mechanism by means of which copper was adsorbed onto MCS perhaps involved an exchange reaction of $\mathrm{Cu}^{2+}$ with $\mathrm{H}^{+}$on the surface and surface complex formation.

Based on the principle of ion-exchange, the more copper that is adsorbed onto MCS, the more hydrogen ions are released; thus the $\mathrm{pH}$ value was decreased. The complex reactions of $\mathrm{Cu}^{2+}$ with hydrous manganese oxide may be written as follows:

$$
\begin{aligned}
& \equiv \mathrm{Mn}-\mathrm{OH}+\mathrm{Cu}^{2+} \leftrightarrow \equiv \mathrm{Mn}-\mathrm{O}^{-} \mathrm{Cu}^{2+}+\mathrm{H}^{+}, \\
& \equiv \mathrm{Mn}-\mathrm{O}^{-}+\mathrm{Cu}^{2+} \leftrightarrow \equiv \mathrm{Mn}-\mathrm{O}^{-} \mathrm{Cu}^{2+}, \\
& 2(\equiv \mathrm{Mn}-\mathrm{OH})+\mathrm{Cu}^{2+} \leftrightarrow\left(\equiv \mathrm{Mn}-\mathrm{O}^{-}\right)_{2} \mathrm{Cu}^{2+}+2 \mathrm{H}^{+}, \\
& 2\left(\equiv \mathrm{Mn}-\mathrm{O}^{-}\right)+\mathrm{Cu}^{2+} \leftrightarrow\left(\equiv \mathrm{Mn}-\mathrm{O}^{-}\right)_{2} \mathrm{Cu}^{2+} .
\end{aligned}
$$

Eqs. (1)-(4) show the hydrogen ion concentration increased with an increasing amount of copper ion adsorbed on the MCS surface. From Fig. 5(c), the adsorption of copper on MCS was highly dependent on the $\mathrm{pH}$. As the $\mathrm{pH}$ increased, the $\mathrm{OH}^{-}$increased, and the surface activity of the MCS increased simultaneously. Besides, in Fig. 5(c), the adsorption curve of $\mathrm{Cu}^{2+}$ displayed three $\mathrm{pH}$ patterns. The adsorption amount increased rapidly with increasing $\mathrm{pH}$ from 2 to 4 and

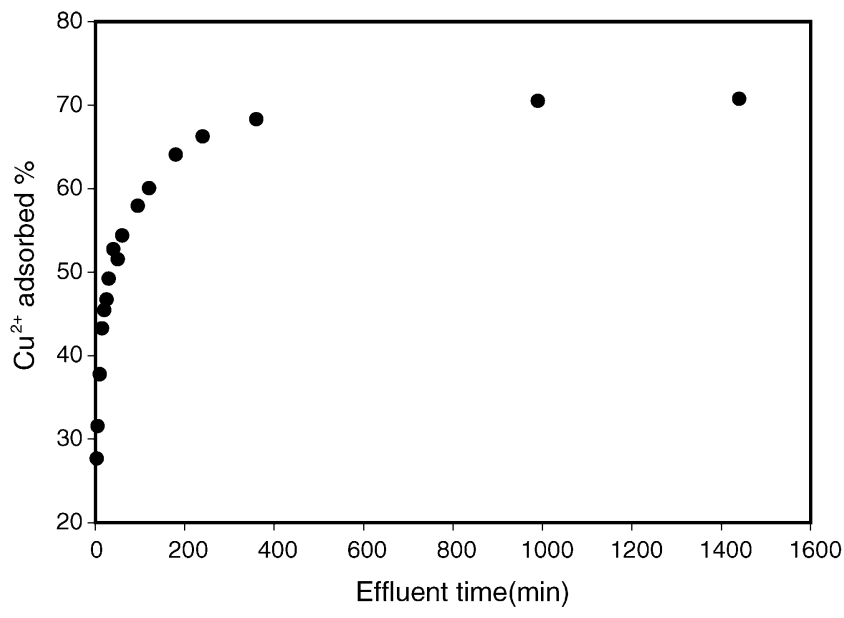

Fig. 6. The adsorption rate of MCS for $\mathrm{Cu}^{2+}$ in the FBR $\left(\mathrm{pH}=6, C_{0}=\right.$ $\left.28 \mathrm{Cu}^{2+} \mathrm{mg} / \mathrm{l}\right)$.

increased slowly with increasing $\mathrm{pH}$ from 4 to 6 . When $\mathrm{pH}$ was over 7 , the precipitation of $\mathrm{Cu}(\mathrm{OH})_{2}$ occurred, and it coated the sand surfaces.

\subsection{Adsorption equilibrium of MCS}

This test of the adsorption equilibrium for MCS included an experiment on the adsorption rate of MCS in the FBR and an adsorption isotherm test using a thermostated shaker.

Fig. 6 shows the copper adsorption rate on MCS in the FBR at an MCS concentration of $20 \mathrm{~g} / \mathrm{l}$. The adsorption amount increased rapidly from 0.39 to $0.7 \mathrm{Cu}^{2+} \mathrm{mg} / \mathrm{g}$-MCS with an increase in the effluent time from 3 to $30 \mathrm{~min}$, and increased slowly from 0.77 to $0.91 \mathrm{Cu}^{2+} \mathrm{mg} / \mathrm{g}$-MCS as the effluent time increased from 60 to $180 \mathrm{~min}$. When the effluent time exceeded $360 \mathrm{~min}$, the adsorbed $\mathrm{Cu}^{2+}$ reached $0.97 \mathrm{Cu}^{2+} \mathrm{mg} / \mathrm{g}$ MCS, the copper adsorbed was $68 \%$ and was $96.5 \%$ of the equilibrium adsorbed amount.

The amount of copper adsorbed by MCS versus the equilibrium concentration of copper ions is further calculated based on the Langmuir and Freundlich adsorption models. Both the Langmuir and Freundlich adsorption isotherms were determined when the equilibrium state was reached. The Langmuir adsorption isotherm at $\mathrm{pH} 5$ was calculated and is shown in Fig. 7. The Langmuir model is expressed as:

$q_{\mathrm{e}}=\frac{Q^{0} b C}{1+b C}$

where $q_{\mathrm{e}}$ and $Q^{0}$ are the observed and ultimate capacity for equilibrium adsorption $(\mathrm{mg} / \mathrm{g}), C$ the residual concentration of copper in the solutions $(\mathrm{mg} / \mathrm{l})$, and $b$ the model constant. From the fitting results of the Langmuir model, the coefficient $Q^{0}$ was 1.025 , the constant $b$ was 0.538 and $R^{2}$ was 0.982 .

Fig. 8 shows the Freundlich adsorption isotherm at $\mathrm{pH}$ 5.The Freundlich adsorption isotherm was determined as:

$q_{\mathrm{e}}=0.3774 C_{\mathrm{e}} \mathrm{e}^{0.3641}$, 


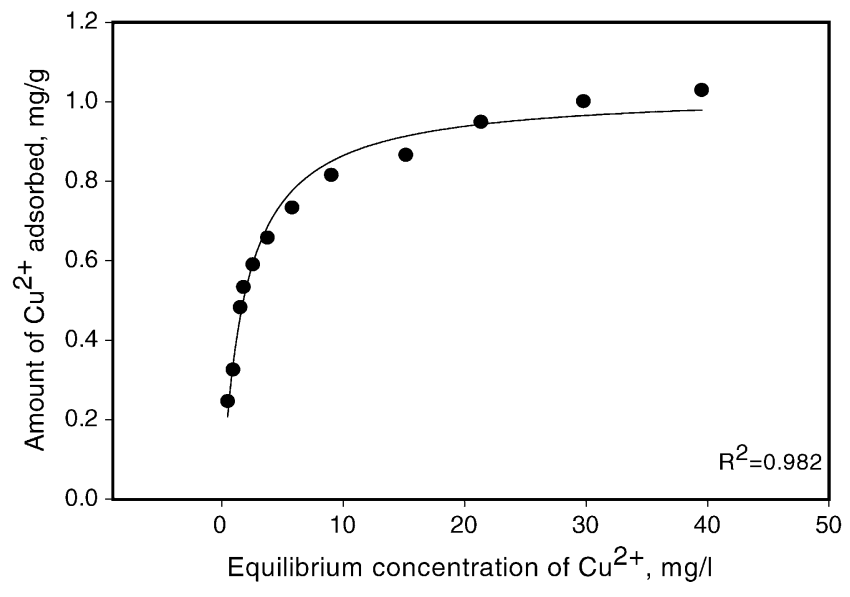

Fig. 7. Langmuir adsorption isotherms of $\mathrm{Cu}^{2+}$ on $\mathrm{MCS}\left(\mathrm{pH}=5, C_{0}=\right.$ $\left.50 \mathrm{Cu}^{2+} \mathrm{mg} / \mathrm{l}\right)$.

where $q_{\mathrm{e}}$ is the amount of copper ions adsorbed on MCS of unit weight $(\mathrm{mg} / \mathrm{g})$, and $C_{\mathrm{e}}$ the residual concentration of copper in the solutions $(\mathrm{mg} / \mathrm{l})$, which have been removed partially under an equilibrium state. In Fig. $8, R^{2}$ is 0.9654.

\subsection{Effect of aeration on copper removal}

The effect of aeration in the copper-contaminated wastewater was also investigated. In this experiment, an air bubble aerator was used, and the flow rate was $5.0 \mathrm{l} / \mathrm{min}$. Fig. 9 shows the variation of the effluent copper concentration with aeration in the influent wastewater. With or without aeration, the effluent copper concentration increased as the effluent time (as soon as the solution effluent from the FBR, the effluent time was 0 ) increased from 0 to $60 \mathrm{~min}$, decreased slowly as the effluent time increased from 60 to $960 \mathrm{~min}$, and then remained constant when the effluent time exceeded $960 \mathrm{~min}$. In the absence of aeration, the effluent copper concentration was $12.55 \mathrm{mg} / \mathrm{l}$ at $30 \mathrm{~min}, 8.40 \mathrm{mg} / \mathrm{l}$ at $960 \mathrm{~min}$, and $8.32 \mathrm{mg} / \mathrm{l}$ at $1440 \mathrm{~min}(24 \mathrm{~h})$. With aeration, the effluent copper concen-

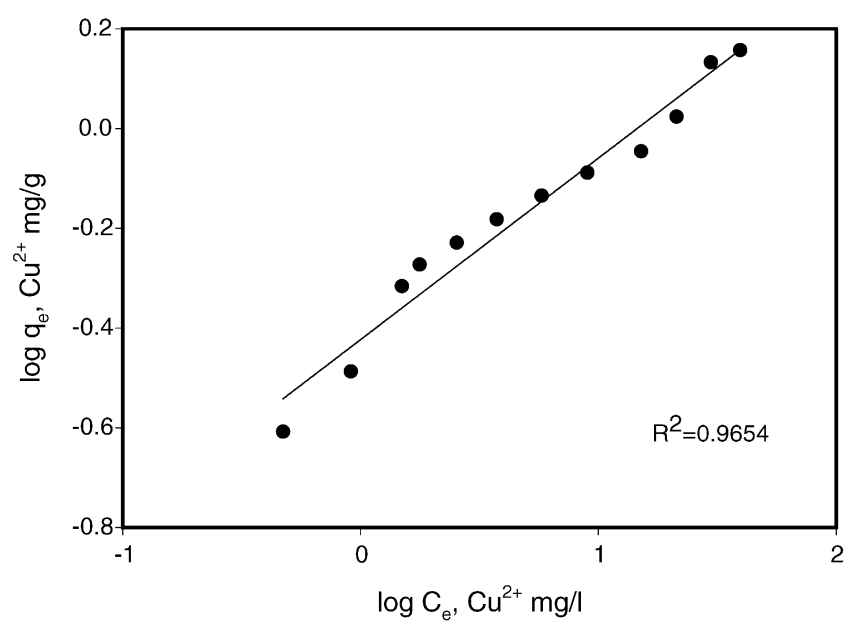

Fig. 8. Freundlich adsorption isotherms of $\mathrm{Cu}^{2+}$ on $\mathrm{MCS}\left(\mathrm{pH}=5, C_{0}=\right.$ $\left.50 \mathrm{Cu}^{2+} \mathrm{mg} / \mathrm{l}\right)$.

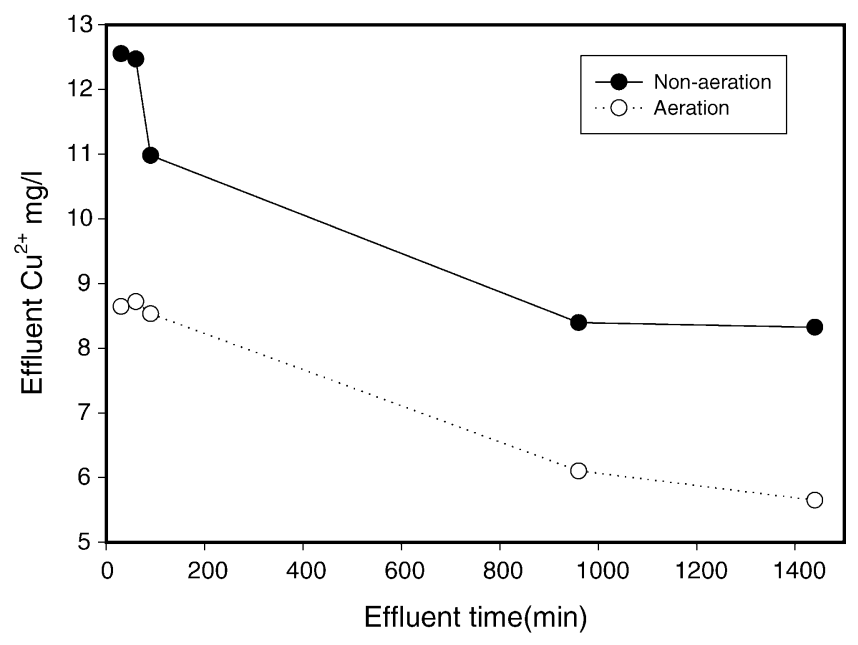

Fig. 9. Variation of the effluent $\mathrm{Cu}^{2+}$ concentration with and without aeration $\left(\mathrm{pH}=6, \mathrm{MCS}\right.$ concentration $=20 \mathrm{~g} / \mathrm{l}$, influent $\left.\mathrm{Cu}^{2+}=30 \mathrm{mg} / \mathrm{l}\right)$.

tration was $8.65 \mathrm{mg} / \mathrm{l}$ at $30 \mathrm{~min}, 6.10 \mathrm{mg} / \mathrm{l}$ at $960 \mathrm{~min}$, and $5.65 \mathrm{mg} / \mathrm{l}$ at $1440 \mathrm{~min}(24 \mathrm{~h})$. The effluent copper concentration in the presence of aeration was lower than that without aeration. The adsorption amount at $24 \mathrm{~h}$ was 1.09 and $0.95 \mathrm{mg} / \mathrm{g}-\mathrm{MCS}$ with and without aeration, respectively.

The results indicate that aeration was conducive for copper adsorption onto the MCS. In this case, when $\mathrm{pH}$ was 6 , under a weak acid solution a little manganese on MCS was dissolved and increased the concentration of $\mathrm{Mn}^{2+}$ in the solution. Aeration oxidized $\mathrm{Mn}^{2+}$ to $\mathrm{MnO}_{2(\mathrm{~s})}$ and coated on the surface of MCS. Comparing with the situation which without aeration, the coated $\mathrm{MnO}_{2 \text { (s) }}$ would increase the number of adsorption sites on MCS and increase copper adsorbed amount.

\section{Conclusions}

Based on the findings of this study, the following conclusions can be made:

(1) The total amount of attached manganese was about $8.03 \mathrm{mg}$ manganese/g-MCS, from the digestion test. The MCS had a large specific surface area, and the SEM result indicated a porous and irregular surface with aggregated particles.

(2) The primary mechanism of copper removal by MCS included electrostatic attraction and surface complex formation. In addition, the precipitation of copper hydroxide potentially led to higher removal efficiency when the initial copper concentration was $30 \mathrm{mg} / \mathrm{l}$ and the $\mathrm{pH}$ value was greater than 6.1.

(3) In the adsorption isotherm test on copper in MCS, the Langmuir adsorption isotherm was more suitable than the Freundlich isotherm. The type of copper adsorption on MCS is probably a monolayer adsorption. 
(4) The copper adsorption amount was increased by aeration because aeration could oxidize $\mathrm{Mn}^{2+}$, producing a solid form of $\mathrm{MnO}_{2}$, and increase the number of adsorption sites on the surface of the MCS.

\section{Acknowledgements}

The authors express their gratitude to the Ministry of Economic affairs of the Republic of China (Contract No.: 91-EC17-A-10-S1-0007) for its financial support.

\section{References}

[1] J.L. Gardea-Torresdey, L. Tang, J.M. Salvador, Copper adsorption by esterified and unesterified fractions of Sphagnum peat moss and its different humic substances, J. Hazard. Mater. 48 (1996) 191-206.

[2] S.E. Bailey, T.J. Olin, R.M. Bricka, D.D. Adrian, A review of potentially low-cost sorbents for heavy metals, Water Res. 33 (1999) 2469-2479.

[3] R. Rao Gadde, A. Herbert, Laitinen, Studies of heavy metal adsorption by hydrous iron and manganese oxides, Anal. Chem. 46 (13) (1974) 2022-2026.

[4] R.P. Bailey, T. Bennett, M.M. Benjamin, Sorption onto and recovery of $\mathrm{Cr}(\mathrm{VI})$ using iron-oxide-coated sand, Water Sci. Technol. 26 (5/6) (1992) 1239-1244.

[5] S.L. Lo, H.T. Jeng, C.H. Lai, Characteristics and adsorption properties of iron-coated sand, Water Sci. Technol. 35 (7) (1997) 63-70.
[6] C.H. Lai, C.Y. Chen, B.L. Wei, S.H. Yeh, Cadmium adsorption on the goethite-coated sand in the presence of humic acid, Water Res. 36 (2002) 4943-4950.

[7] G. Hor'anyi, P. Jo'o, Comparative radiotracer study of the adsorption of sulfate and pertechnetate ions on $\gamma-\mathrm{Al}_{2} \mathrm{O}_{3}$, J. Colloid Interf. Sci. 243 (2001) 46-51.

[8] Tao Zuyi, Li Weijuan, Z. Fuming, D. Youqian, Yu Zhen, Am(III) adsorption on oxides of aluminium and silicon: effects of humic substances, pH, and ionic strength, J. Colloid Interf. Sci. 265 (2003) 221-226.

[9] S.B. Kanungo, K.M. Paroda, Interfacial behavior of some synthetic $\mathrm{MnO} 2$ samples during their adsorption of $\mathrm{Cu}^{2+}$ and $\mathrm{Ba}^{2+}$ from aqueous solution at $300 \mathrm{~K}$, J. Colloid Interf. Sci. 98 (1984) 252260.

[10] W.D. Harms, R.B. Robinson, Softening by fluidized-bed crystallizers, J. Environ. Eng., ASCE 118 (1992) 513-529.

[11] H. Aktor, Continuous high-rate removal of chromate in a fluidized bed without sludge generation, Water Sci. Technol. 30 (7) (1994) $31-40$.

[12] P.B. Nielsen, T.C. Christensen, M. Vendrup, Continuous removal of heavy metals from FGD wastewater in a fluidized bed without sludge generation, Water Sci. Technol. 36 (2/3) (1997) 391397.

[13] M. Scholler, J. Dijk, D. Wilms, Recovery of heavy metals by crystallization, Metal Finish. 85 (11) (1987) 31-34.

[14] M. Scholler, J. Dijk, D. Wilms, Fluidized bed pellet reactor to recovery metals or anions, Metal Finish. 89 (11) (1991) 46-50.

[15] D.A. Wilms, K. Vercamst, J.C. Dijk, Recovery of silver by crystallization of silver carbonate in a fluidized-bed reactor, Water Res. 26 (1992) 235-239.

[16] F.M.M. Morel, J.G. Hering, Principles and Applications of Aquatic Chemistry, Wiley, New York, 1993. 